\title{
Relative Age, Biological Maturation and Anaerobic Characteristics in Elite Youth Soccer Players
}

Authors

Affiliations

\author{
D. Deprez ${ }^{1}$, A. J. Coutts ${ }^{2}$, J. Fransen ${ }^{1}$, F. Deconinck ${ }^{1}$, M. Lenoir ${ }^{1}$, R. Vaeyens ${ }^{1}$, R. Philippaerts ${ }^{1}$
}

${ }^{1}$ Movement and Sports Sciences, Ghent University, Ghent, Belgium

${ }^{2}$ School of Leisure, Sport \& Tourism, Lindfield, University of Technology, Sydney, Australia
Key words

talent selection

explosive strength

speed

peak height velocity

birth date accepted after revision December 12, 2012

Bibliography DOI http://dx.doi.org/ 10.1055/s-0032-1333262 Published online: May 22, 2013

Int J Sports Med 2013; 34: 897-903 @ Georg Thieme Verlag KG Stuttgart · New York ISSN 0172-4622

Correspondence

Dieter Deprez

Movement and Sports Sciences Ghent University

Watersportlaan 2 9000 Ghent

Belgium

Tel.: + 32/9/2649441

Fax: + 32/9/264 6484

Dieter.Deprez@UGent.be

\section{Abstract}

$\nabla$

Being relatively older and having an advanced biological maturation status have been associated with increased likelihood of selection in young elite soccer players. The aims of the study were to investigate the presence of a relative age effect (RAE) and the influence of birth quarter on anthropometry, biological maturity and anaerobic parameters in 374 elite Belgian youth soccer players. The sample was divided into 3 age groups, each subdivided into 4 birth quarters (BQ). Players had their APHV estimated and height, weight, SBJ, CMJ, sprint 5 and $30 \mathrm{~m}$ were assessed. Overall, more players were born in BQ1 (42.3\%) compared with players born in BQ4

\section{Introduction}

$\nabla$

Similar to many other sports, youth soccer competitions are organized into annual age groups according to chronological age with specific cutoff dates. Consequently, players who are born early in the selection year (e.g. first birth quarter) take advantage of this subtle chronological lead and are more likely to be selected compared with peers born later in the selection year (e.g. fourth birth quarter). This difference in chronological age is referred to as relative age, and its consequences are known as the relative age effect (RAE). Being chronologically older within an annual age cohort provides significant attainment advantages when compared with those who are chronologically younger. As a consequence, this RAE leads to skewed birth date distributions in many sports with overrepresentation of youth and professional level athletes born in the first part of the selection year [12,13,22,29]. Similar to relative age advantages, advanced biological maturity has also been associated with an increased likelihood of selection in youth ath-
(13.7\%). Further, MANCOVA revealed no differences in all parameters between the 4 BQ's, controlled for age and APHV. These results suggest that relatively youngest players can offset the RAE if they enter puberty earlier. Furthermore, the results demonstrated possible differences between BQ1 and BQ4, suggesting that caution is necessary when estimating differences between players because of large discrepancies between statistical and practical significance. These findings also show that coaches should develop realistic expectations of the physical abilities of younger players and these expectations should be made in the context of biological characteristics rather than chronological age-based standards.

letes. It has been previously shown that youth athletes who are advanced in biological maturation perform better in strength, speed, power and endurance compared with less mature agematched counterparts $[9,18,30]$, others have demonstrated that athletes born earlier in the selection year tend to be taller and heavier than their later born peers $[4,13]$. As a result, coaches and talent scouts have been likely to favour the physically advanced players. Indeed, Sherar et al. [25] reported that team selectors more frequently select taller, heavier and early maturing ice-hockey players who have birthdates early in the selection year. In contrast, Hirose [13] and Deprez et al. [8] revealed no differences in height and body mass between the 4 birth quarters in elite Japanese soccer players, aged 9-15 years and elite Belgian soccer players, aged 9-17 years, respectively. Notably however, the small number of players born later in the selection year possessed advanced physical and biological maturation, which likely explains why these players were successfully selected into elite representative teams $[8,13]$. Carling et al. [4] showed simi- 
lar trends in French 14-year-old elite soccer players reporting that relatively older players are not always linked to advantages in physical and physiological components. In addition, Segers et al. [24] reported no differences in endurance between early and late maturing youth soccer players when adjusted for lean body mass. Collectively, these studies show that biological maturity can also influence selection of youth athletes. Indeed, the combination of increased biological maturity and an older age, and their relation to physical performance appears to provide young athletes significant advantage.

The physical factors that are associated with successful soccer have been well described [27]. Whilst improved high intensity running capacity has been shown to distinguish between players of different levels [21], other skills that require increased anaerobic capacity and neuromuscular power such as sprints, jumps, duels and kicking have also been shown to discriminate between different levels of soccer players [6]. For example, Vaeyens et al. [30] revealed better performances of skills requiring increased anaerobic power (sprint performance, vertical jump and standing broad jump) in elite youth soccer players when compared with sub-elite and non-elite youth soccer players (U13-U14).

To our knowledge, little is known about the age-related variation in anaerobic performance in elite youth soccer players. Additionally, only a few studies investigated the relationship between the RAE, biological maturation and anaerobic performance $[4,13]$. Therefore, the aims of the study were to investigate 1 ) the presence of a RAE and 2) the influence of the possible RAE (or birth quarter) on anthropometric variables, an estimation of biological maturity and some important anaerobic parameters in Flemish, elite youth soccer players aged $11-16$ years.

\section{Methods}

$\nabla$

\section{Participants and design}

Elite youth soccer players from 2 professional clubs from the Belgian first division (Jupiler Pro League) participated in the study. The age-range of the players was $10.6-16.6$ years. All players and their parents or legal representatives were fully informed of experimental procedures before giving their written informed consent. The study was approved by the Ethic Committee of the Ghent University Hospital and the study was performed in accordance with the ethical standards of the International Journal of Sports Medicine [10].

The sample included 555 data points from 374 individual soccer players, all born between 1993-2003. Players were divided into 3 different age categories: U13 (aged 10.6-12.6 years; $n=146$ ), U15 (aged 12.6-14.6 years; $n=162$ ) and U17 (aged 14.6-16.6 years; $n=247)$.

Data were collected on 15 different test periods over 5 years between August 2007 and August 2011. Within each season, the test periods were scheduled at the same time within the soccer season: preparation period (August), game period 1 (before winter break, October-November), game period 2 (after winter break, February) and at the end of the season (April, this only in 2008 and 2009). Accordingly, a small number of players had several measures taken within each age category. To ensure that only one measurement was taken for each player within each age category, the best performance on all variables was taken. Data included only one measurement for each player per test year to ensure that players had a maximum of 5 measurements from each of the different age categories (n players with one measurement $=255$; $n$ players with 2 measurements $=76$; $n$ players with 3 measurements $=29$; n players with 4 measurements $=9$; n players with five measurements $=5$ ).

All participants were categorized into four birth quarters (BQ) according to their month of birth. The cut-off date for the selection year for youth soccer players in Belgium runs from January 1 to December 31, so players were categorized in these 4 birth quarters: BQ1: January-March, BQ2: April-June, BQ3: July-September, BQ4: October-December.

\section{Measurements}

Prior to the testing of anaerobic performance characteristics, the anthropometrical characteristics of each player were assessed: height $(0.1 \mathrm{~cm}$, Harpenden Portable Stadiometer, Holtain, UK), sitting height $(0.1 \mathrm{~cm}$, Harpenden Sitting Height Table, Holtain, UK) and body mass $(0.1 \mathrm{~kg}$, total body composition analyzer, TANITA BC-420SMA, Japan) according to previously described procedures (Lohman, 1988) and manufacturer's guidelines.

Estimation of biological maturation of each individual was calculated by the non-invasive method, based on anthropometric variables described by Mirwald et al. [20]. Equation 3 predicts the years from peak height velocity as a measure of maturity offset. The age of peak height velocity (APHV) is then calculated as the difference between the chronological age and the predicted time (in years) from peak height velocity. APHV is an indicator of biological maturity representing the time of maximum growth during adolescence.

After a $10 \mathrm{~min}$ standardized warm-up period, the players completed a test battery in a fixed order to assess motor competence and physiological fitness. In this study, 3 measurements of anaerobic performance were applied for further analysis. To evaluate explosive leg power, counter movement jump (CMJ) and standing broad jump (SBJ) were performed. CMJ was conducted according to the methods described by Bosco et al. [3] with the arms kept in the akimbo position to minimize their contribution recorded by an OptoJump (MicroGate, Italy). The highest of 3 jumps was used for further analysis $(0.1 \mathrm{~cm})$. The SBJ is part of the Eurofit test battery and was conducted according to the guidelines of the Council of Europe [7] $(1 \mathrm{~cm})$. The players also performed 4 maximal sprints of $30 \mathrm{~m}$ with split times at $5 \mathrm{~m}, 10 \mathrm{~m}, 20 \mathrm{~m}$ and $30 \mathrm{~m}$, with the fastest $5 \mathrm{~m}$ and the fastest $30 \mathrm{~m}$ used for analysis in order to ensure a maximal value (i.e., the fastest $5 \mathrm{~m}$ is not necessarily the split time from the fastest $30 \mathrm{~m}$ sprint). Between each $30 \mathrm{~m}$ sprint, players had $25 \mathrm{~s}$ to recover. The sprint performance was recorded using MicroGate RaceTime 2 chronometry and Polifemo light photocells (Bolzano, Italy) $(0.001 \mathrm{~s})$. All tests were completed on an indoor tartan running track at a temperature between $15-20^{\circ} \mathrm{C}$. All subjects were familiarized with the test procedures and performed the tests in running shoes, except for the SBJ which was conducted with bare feet.

\section{Statistical analyses}

All statistical analyses were completed using SPSS for windows (version 19.0). Descriptive statistics are presented as means \pm standard deviations (SD). First, differences between the observed and the expected birth date distributions were investigated with chi-square statistics. Expected birth date distributions were calculated in accordance with the birth rate of the Flemish population between 1991 and 2000 (National Institute of Statistics) using weighted means. Second, within each age category, differ- 
ences between birth quarters (independent variable) were calculated using 1-way ANOVA with chronological age (CA) and APHV as dependent variables. Multivariate analysis of covariance (MANCOVA) with CA and APHV as covariates and height, weight, CMJ, SBJ, $5 \mathrm{~m}$ and $30 \mathrm{~m}$ sprint as dependent variables, was used to investigate differences between birth quarters (independent variable). Chronological age and APHV were controlled for as these are potential confounding factors in the analysis. Minimal statistical significance was set at $\mathrm{P}<0.05$. Follow-up univariate analyses using Bonferroni post hoc test were used where appropriate.

Since several authors described large differences in anthropometrical characteristics and physical capacities between chronologically older and younger players within the same age group $[9,18,30]$, further analysis was conducted to identify smallest worthwhile differences between players born in the first and fourth birth quarter, using the method outlined by Hopkins $[14,15]$. This approach represents a contemporary method of data analysis that uses confidence intervals in order to calculate the probability that a difference is clinically beneficial, trivial or harmful. The smallest worthwhile difference was set at Cohen's effect size of 0.2 , representing the hypothetical, smallest difference between birth quarter 1 and 4 . Cohen's $d$ effect sizes (ES) and thresholds $(0.2,0.6,1.2,2.0,4.0$ for trivial, small, moderate, large, very large and extremely large) were also used to compare the magnitude of the differences in anthropometrical characteristics and physical parameters between BQ1 and BQ4 [15]. Where the chance of benefit and harm were both calculated to be $\geq 5 \%$, the true effect was deemed unclear. When clear interpretation was definitively possible, a qualitative descriptor was assigned to the following quantitative chances of benefit: $<0.5 \%$ : most unlikely; 0.5-5\%: very unlikely; 5-25\%: unlikely; 25-75\%: possibly; 75-95\%: likely; 95-99.5\%: very likely; >99.5: most likely [15].

\section{Results}

$\nabla$

\section{Birth date distribution}

From the total sample of U13-U17 players, the birth date distribution differed significantly from the Flemish population $\left(X_{3}^{2}=104.6, P<0.001\right)$. Significantly more players were born in the first quarter of the selection year compared with the fourth quarter with a decreasing number of players from BQ1 to BQ4 (BQ1: 42.3\%; BQ2: 26.1\%; BQ3: 17.8\%; BQ4: 13.7\%). This observation was apparent for each age group. The proportion of players born in BQ1 varied between 40.1 and $44.4 \%$, while proportion of players born in BQ4 varied between 12.3 and 14.8\%. $\odot$ Table 1 shows birth date distributions across all birth quarters for the total sample and for each age group.

\section{Anthropometric variables}

- Table 2 shows no differences for height and weight between BQ groups in all age groups except for height in the U15 age group. In the U15 age-group, players born in BQ2 $(162.7 \pm 8.5 \mathrm{~cm})$ and BQ3 $(162.1 \pm 7.9 \mathrm{~cm})$ were significantly $(\mathrm{P}<0.05 ; \mathrm{F}=2.923)$ taller than players born in BQ4 $(157.8 \pm 7.9 \mathrm{~cm})$. Both chronological age and APHV were significant covariates for height and weight in all age groups. ANOVA revealed no significant differences for APHV between birth quarters in all age groups.

\section{Anaerobic parameters}

Within all age groups, MANCOVA demonstrated no significant differences between birth quarters for all anaerobic performance characteristics when CA and APHV were controlled for (U13: $\mathrm{P}=0.570, \mathrm{~F}=0.907 ; \mathrm{U15}: \mathrm{P}=0.337, \mathrm{~F}=1.112 ; \mathrm{U17}: \mathrm{P}=0.770$, $\mathrm{F}=0.741$ ). Besides, the covariates, CA and APHV significantly confound all investigated variables in all age groups (CA: U13, $\mathrm{P}<0.001, \mathrm{~F}=99.593 ; \mathrm{U15}, \mathrm{P}<0.001, \mathrm{~F}=75.958 ; \mathrm{U17}, \mathrm{P}<0.001$, $\mathrm{F}=26.805 ; A P H V: \mathrm{U} 13, \mathrm{P}<0.001, \mathrm{~F}=140.739 ; \mathrm{U} 15, \mathrm{P}<0.001$, $\mathrm{F}=263.965 ; \mathrm{U} 17, \mathrm{P}<0.001, \mathrm{~F}=117.312$ ).

Further ANCOVA analyses for each variable revealed that for all age groups, chronological age was significant as a covariate between birth quarters for all anaerobic parameters, except for the 5-m and 30-m sprint times within the U13 age group ( $\bullet$ Table 2 ). In addition, within the U13 age group, the covariate APHV did not significantly confound the anaerobic performance characteristics. This is in contrast with the U15 and U17 age group, where APHV did significantly confound all anaerobic performance characteristics.

\section{Practical/clinical significance}

Where the statistical analyses revealed no differences between birth quarters in each age group, analyses of practical significance showed contrasting results. Especially in the U13 age group, differences were assigned as possible to likely benefits for players in BQ1 relative to BQ4, supported by small to moderate ES's (0.31-0.97). Trivial to small ES's (0.00-066) were found in the U15 and U17 age group resulting in unclear to likely chances of benefit for players born in BQ1 ( $\bullet$ Table 3). Comparison of semester 1 and 2 values revealed similar results.

Table 1 Birth date distribution per quarter (BQ) by age group (n (\%)).

\begin{tabular}{|c|c|c|c|c|c|c|}
\hline \multirow[t]{2}{*}{ Age Category } & \multicolumn{6}{|c|}{ BQ } \\
\hline & $n$ & BQ 1 & BQ 2 & BQ 3 & BQ 4 & $X^{2}{ }_{3}(B Q)$ \\
\hline U13-U17 & 555 & 235 (42.3\%) & 145 (26.1\%) & $99(17.8 \%)$ & $76(13.7 \%)$ & $104.610^{*}$ \\
\hline Flanders & & $81,921(25.0 \%)$ & $83,539(25.4 \%)$ & $84,741(25.8 \%)$ & $78,124(23.8 \%)$ & \\
\hline U13 & 146 & $64(43.8 \%)$ & $40(27.4 \%)$ & $24(16.4 \%)$ & $18(12.3 \%)$ & $34.498 *$ \\
\hline Flanders & & 15,827 (24.9\%) & 16,135 (25.3\%) & $16,525(26.0 \%)$ & $15,178(23.8 \%)$ & \\
\hline U15 & 162 & $72(44.4 \%)$ & $36(22.2 \%)$ & $30(18.5 \%)$ & $24(14.8 \%)$ & $34.202^{*}$ \\
\hline Flanders & & $16,292(24.9 \%)$ & $16,687(25.5 \%)$ & $16,816(25.7 \%)$ & $15,610(23.9 \%)$ & \\
\hline U17 & 247 & $99(40.1 \%)$ & $69(27.9 \%)$ & $45(18.2 \%)$ & $34(13.8 \%)$ & $38.240^{*}$ \\
\hline Flanders & & 16,999 (25.1\%) & $17,214(25.4 \%)$ & $17,502(25.8 \%)$ & 15,997 (23.6\%) & \\
\hline
\end{tabular}

$* P<0.001$ 
Table 2 Chronological age (CA), estimation of biological maturity (APHV) and anthropometric variables of elite youth soccer players (U13-U17) across 4 birth quarters (BQ1-BQ4).

\begin{tabular}{|c|c|c|c|c|c|c|c|c|c|c|c|}
\hline & Variable & BQ1 & BQ2 & BQ3 & BQ4 & & Cov & Iriates & & & \\
\hline Category & & & & & & $F(C A)$ & $P$ & $F(A P H V)$ & $P$ & $F(B Q)$ & $P$ \\
\hline \multirow[t]{9}{*}{ U13 } & & $n=64$ & $n=40$ & $n=24$ & $n=18$ & & & & & & \\
\hline & CAge (years) & $12.0 \pm 0.5_{\mathrm{A}}$ & $11.7 \pm 0.5_{\mathrm{A}}$ & $11.3 \pm 0.5_{B}$ & $11.3 \pm 0.5_{B}$ & - & - & - & - & $15.997^{\#}$ & $* * *$ \\
\hline & APHV (years) & $13.7 \pm 0.4$ & $13.6 \pm 0.4$ & $13.6 \pm 0.3$ & $13.6 \pm 0.3$ & - & - & - & - & $1.106^{\#}$ & $P=0.349$ \\
\hline & height (cm) & $151.1 \pm 6.5$ & $150.6 \pm 6.5$ & $145.8 \pm 4.9$ & $145.5 \pm 5.0$ & 326.953 & $* * *$ & 428.864 & $* * *$ & 1.022 & $P=0.385$ \\
\hline & weight (kg) & $39.1 \pm 4.9$ & $39.2 \pm 5.7$ & $36.9 \pm 5.2$ & $36.1 \pm 4.0$ & 247.464 & $* * *$ & 344.424 & $* * *$ & 1.345 & $P=0.262$ \\
\hline & $\mathrm{SBJ}(\mathrm{cm})$ & $177 \pm 14$ & $176 \pm 14$ & $174 \pm 13$ & $173 \pm 10$ & 5.619 & * & 0.574 & $P=0.450$ & 0.081 & $P=0.970$ \\
\hline & CMJ $(\mathrm{cm})$ & $24.5 \pm 3.5$ & $24.6 \pm 2.6$ & $24.1 \pm 3.2$ & $23.3 \pm 3.6$ & 5.368 & * & 3.708 & $P=0.056$ & 0.487 & $P=0.692$ \\
\hline & sprint $5 \mathrm{~m}(\mathrm{~s})$ & $1.23 \pm 0.07$ & $1.22 \pm 0.07$ & $1.26 \pm 0.05$ & $1.25 \pm 0.06$ & 1.144 & $P=0.287$ & 0.001 & $P=0.977$ & 1.664 & $P=0.177$ \\
\hline & sprint 30m (s) & $5.17 \pm 0.21$ & $5.17 \pm 0.18$ & $5.27 \pm 0.17$ & $5.23 \pm 0.29$ & 1.453 & $P=0.230$ & 0.458 & $P=0.500$ & 0.776 & $P=0.509$ \\
\hline \multirow[t]{9}{*}{ U15 } & & $n=72$ & $n=36$ & $n=30$ & $n=24$ & & & & & & \\
\hline & CAge (years) & $14.0 \pm 0.5_{\mathrm{A}}$ & $13.8 \pm 0.5_{\mathrm{A}}$ & $13.6 \pm 0.5_{B}$ & $13.2 \pm 0.5_{B}$ & - & - & - & - & $12.696^{\#}$ & $* * *$ \\
\hline & APHV (years) & $14.0 \pm 0.6$ & $13.9 \pm 0.6$ & $14.0 \pm 0.6$ & $13.9 \pm 0.6$ & - & - & - & - & $0.203^{\#}$ & \\
\hline & height (cm) & $163.4 \pm 9.1_{\mathrm{A}, \mathrm{B}}$ & $162.7 \pm 8.5_{\mathrm{A}}$ & $162.1 \pm 7.9_{\mathrm{A}}$ & $157.8 \pm 7.9_{B}$ & 269.445 & $* * *$ & 989.974 & $* * *$ & 2.923 & * \\
\hline & weight $(\mathrm{kg})$ & $50.7 \pm 8.6$ & $50.7 \pm 8.4$ & $49.0 \pm 8.4$ & $46.8 \pm 9.8$ & 158.300 & $* * *$ & 635.674 & $* * *$ & 0.584 & $P=0.627$ \\
\hline & $\mathrm{SBJ}(\mathrm{cm})$ & $193 \pm 17$ & $196 \pm 18$ & $190 \pm 14$ & $190 \pm 16$ & 20.610 & $* * *$ & 29.025 & $* * *$ & 0.886 & $P=0.450$ \\
\hline & $\mathrm{CMJ}(\mathrm{cm})$ & $27.7 \pm 4.2$ & $29.2 \pm 3.8$ & $28.0 \pm 4.6$ & $26.7 \pm 4.5$ & 16.294 & $* * *$ & 16.199 & $* * *$ & 1.933 & $P=0.127$ \\
\hline & sprint $5 \mathrm{~m}(\mathrm{~s})$ & $1.18 \pm 0.07$ & $1.17 \pm 0.07$ & $1.17 \pm 0.07$ & $1.21 \pm 0.07$ & 8.460 & ** & 9.167 & ** & 0.680 & $P=0.566$ \\
\hline & sprint $30 \mathrm{~m}$ (s) & $4.86 \pm 0.24$ & $4.80 \pm 0.22$ & $4.91 \pm 0.32$ & $4.96 \pm 0.28$ & 41.916 & $* * *$ & 27.999 & $* * *$ & 1.567 & $P=0.200$ \\
\hline \multirow[t]{9}{*}{ U17 } & & $n=99$ & $n=69$ & $n=45$ & $n=34$ & & & & & & \\
\hline & CAge (years) & $15.9 \pm 0.5_{\mathrm{A}}$ & $15.8 \pm 0.5_{\mathrm{A}}$ & $15.5 \pm 0.5_{B}$ & $15.3 \pm 0.5_{B}$ & - & - & - & - & $18.663^{\#}$ & $* * *$ \\
\hline & APHV (years) & $14.0 \pm 0.6$ & $13.9 \pm 0.5$ & $14.0 \pm 0.6$ & $14.0 \pm 0.6$ & - & - & - & - & $0.990^{\#}$ & $P=0.398$ \\
\hline & height (cm) & $174.0 \pm 6.5$ & $175.1 \pm 6.3$ & $172.1 \pm 6.3$ & $171.9 \pm 5.9$ & 82.329 & $* * *$ & 492.053 & $* * *$ & 0.325 & $P=0.807$ \\
\hline & weight $(\mathrm{kg})$ & $62.2 \pm 8.4$ & $64.7 \pm 7.3$ & $60.3 \pm 8.0$ & $59.5 \pm 7.8$ & 69.949 & $* * *$ & 395.959 & $* * *$ & 1.866 & $P=0.136$ \\
\hline & $\mathrm{SBJ}(\mathrm{cm})$ & $219 \pm 17$ & $221 \pm 18$ & $214 \pm 17$ & $215 \pm 16$ & 52.374 & $* * *$ & 52.006 & $* * *$ & 0.784 & $P=0.504$ \\
\hline & $\mathrm{CMJ}(\mathrm{cm})$ & $33.6 \pm 4.7$ & $34.5 \pm 4.5$ & $32.9 \pm 4.3$ & $33.1 \pm 4.0$ & 42.656 & $* * *$ & 40.658 & $* * *$ & 1.667 & $P=0.175$ \\
\hline & sprint $5 \mathrm{~m}(\mathrm{~s})$ & $1.10 \pm 0.07$ & $1.09 \pm 0.07$ & $1.12 \pm 0.07$ & $1.10 \pm 0.05$ & 10.204 & ${ }^{* *}$ & 4.008 & * & 1.283 & $P=0.281$ \\
\hline & sprint $30 \mathrm{~m}$ (s) & $4.46 \pm 0.20$ & $4.43 \pm 0.18$ & $4.52 \pm 0.19$ & $4.52 \pm 0.20$ & 45.431 & $* * *$ & 50.162 & $* * *$ & 0.701 & $P=0.552$ \\
\hline
\end{tabular}

Means having a different subscript are significantly different at $p<0.05$. Between-subjects effects for covariates and BQ are significant at: $p<0.05 ;{ }^{* *} p<0.01 ;{ }^{* * *} p<0.001$; n.s. not significant. ${ }^{*} \mathrm{~F}$ - and P-values for one way analysis of variance

Table 3 Mean differences, effect sizes and chances of benefit for differences between BQ1 and BQ4 for anthropometrical and anaerobic parameters in each age-group.

\begin{tabular}{|c|c|c|c|c|c|c|c|c|c|}
\hline $\begin{array}{l}\text { Age } \\
\text { Category }\end{array}$ & Variable & $\begin{array}{l}\text { BQ1 } \\
\text { (Mean; } \pm 90 \% \mathrm{CL} \text { ) }\end{array}$ & $\begin{array}{l}\text { BQ4 } \\
\text { (Mean; } \pm 90 \% \mathrm{CL} \text { ) }\end{array}$ & $\begin{array}{l}\text { Mean diff } \\
( \pm 90 \% \mathrm{CL})\end{array}$ & ES & $\begin{array}{l}\text { Magni- } \\
\text { tude }\end{array}$ & SWD (\%) & $\begin{array}{l}\text { \% chances } \\
\text { B (T/H) }\end{array}$ & $\begin{array}{l}\text { Chances of } \\
\text { benefit } \\
\text { (Qualitative) }\end{array}$ \\
\hline \multirow[t]{7}{*}{ U13 } & & $n=64$ & $n=18$ & & & & & & \\
\hline & height $(\mathrm{cm})$ & $151.1 ; \pm 1.4$ & $145.5 ; \pm 2.0$ & $5.6 ; \pm 2.8$ & 0.97 & moderate & $1.3(0.9)$ & $99(1 / 0)$ & very likely \\
\hline & weight $(\mathrm{kg})$ & $39.1 ; \pm 1.0$ & $36.1 ; \pm 1.6$ & $3.1 ; \pm 2.1$ & 0.67 & moderate & $1.0(2.5)$ & $47(53 / 0)$ & possibly \\
\hline & $\mathrm{SBJ}(\mathrm{cm})$ & $177 ; \pm 2.8$ & $173 ; \pm 4.0$ & $3.7 ; \pm 5.7$ & 0.33 & small & $2.6(1.5)$ & $34(65 / 1)$ & possibly \\
\hline & $\mathrm{CMJ}(\mathrm{cm})$ & $24.5 ; \pm 0.7$ & $23.3 ; \pm 1.5$ & $1.1 ; \pm 1.6$ & 0.34 & small & $0.7(3.0)$ & $61(37 / 2)$ & possibly \\
\hline & sprint $5 \mathrm{~m}(\mathrm{~s})$ & $1.23 ; \pm 0.01$ & $1.25 ; \pm 0.03$ & $-0.02 ; \pm 0.03$ & -0.31 & small & $0.01(1.1)$ & $62(37 / 1)$ & possibly \\
\hline & sprint $30 \mathrm{~m}(\mathrm{~s})$ & $5.17 ; \pm 0.04$ & $5.23 ; \pm 0.12$ & $-0.06 ; \pm 0.1$ & -0.24 & small & $0.05(0.9)$ & $52(45 / 3)$ & possibly \\
\hline \multirow[t]{7}{*}{ U15 } & & $n=72$ & $n=24$ & & & & & & \\
\hline & height (cm) & $163.4 ; \pm 1.8$ & $157.8 ; \pm 2.8$ & $5.6 ; \pm 3.5$ & 0.66 & moderate & $1.8(1.1)$ & $94(6 / 0)$ & likely \\
\hline & weight $(\mathrm{kg})$ & $50.7 ; \pm 1.7$ & $46.8 ; \pm 3.4$ & $3.9 ; \pm 3.5$ & 0.42 & small & $1.8(3.6)$ & $4(96 / 0)$ & very unlikely \\
\hline & $\mathrm{SBJ}(\mathrm{cm})$ & $193 ; \pm 3.3$ & $190 ; \pm 5.7$ & $3.2 ; \pm 6.5$ & 0.18 & trivial & $3.4(1.8)$ & $16(83 / 1)$ & unlikely \\
\hline & $\mathrm{CMJ}(\mathrm{cm})$ & $27.7 ; \pm 0.8$ & $26.7 ; \pm 1.6$ & $1.0 ; \pm 1.7$ & 0.23 & small & $0.8(3.1)$ & $2(98 / 0)$ & very unlikely \\
\hline & sprint $5 \mathrm{~m}(\mathrm{~s})$ & $1.18 ; \pm 0.01$ & $1.21 ; \pm 0.03$ & $-0.03 ; \pm 0.03$ & -0.43 & small & $0.01(1.2)$ & $76(24 / 0)$ & likely \\
\hline & sprint $30 \mathrm{~m}$ (s) & $4.86 ; \pm 0.05$ & $4.96 ; \pm 0.10$ & $-0.10 ; \pm 0.11$ & -0.38 & small & $0.05(1.1)$ & $74(26 / 0)$ & possibly \\
\hline \multirow[t]{7}{*}{ U17 } & & $n=99$ & $n=34$ & & & & & & \\
\hline & height $(\mathrm{cm})$ & $174.0 ; \pm 1.1$ & $171.9 ; \pm 1.7$ & $2.1 ; \pm 2.1$ & 0.34 & small & $1.3(0.7)$ & $51(2 / 47)$ & unclear \\
\hline & weight (kg) & $62.2 ; \pm 1.4$ & $59.5 ; \pm 2.3$ & $2.7 ; \pm 2.8$ & 0.33 & small & $1.7(2.7)$ & $1(86 / 0)$ & unlikely \\
\hline & $\mathrm{SBJ}(\mathrm{cm})$ & $219 ; \pm 2.9$ & $215 ; \pm 4.8$ & $4.4 ; \pm 5.6$ & 0.24 & small & $3.4(1.6)$ & $39(61 / 0)$ & possibly \\
\hline & $\mathrm{CMJ}(\mathrm{cm})$ & $33.6 ; \pm 0.8$ & $33.1 ; \pm 1.2$ & $0.4 ; \pm 1.5$ & 0.11 & trivial & $0.9(2.7)$ & $1(99 / 0)$ & very unlikely \\
\hline & sprint $5 \mathrm{~m}(\mathrm{~s})$ & $1.10 ; \pm 0.01$ & $1.10 ; \pm 0.01$ & $0.00 ; \pm 0.02$ & 0.00 & trivial & $0.01(1.1)$ & $24(69 / 7)$ & unclear \\
\hline & sprint $30 \mathrm{~m}$ (s) & $4.46 ; \pm 0.03$ & $4.52 ; \pm 0.06$ & $-0.06 ; \pm 0.07$ & -0.30 & small & $0.04(0.9)$ & $71(28 / 0)$ & possibly \\
\hline
\end{tabular}

$\mathrm{CL}=$ Confidence Limits; Mean diff= Mean difference; $\mathrm{ES}=$ Cohens' $\mathrm{d}$ effect size; SWD =Smallest Worthwhile Difference; $\mathrm{B}(\mathrm{T} / \mathrm{H})=$ Beneficial $($ Trivial/Harmful) 


\section{Discussion}

\section{$\nabla$}

The aim of this study was to investigate the influence of birth quarter on anthropometric variables, an estimation of biological maturational status and anaerobic parameters in 374 Belgian, elite youth soccer players. In general, significantly more players were born in the first quarter of the selection year compared with players born in all other quarters (Q1 $>$ Q2 $>$ Q3 $>$ Q4). Further, no statistical differences were observed in any anthropometric variables in all age groups, except for height in the U15 age group where players born in BQ2 and BQ3 were taller than players born in BQ4. Similarly, no differences were found in anaerobic performance characteristics between the birth quarters in all age groups. Further, the results were supported by analyses of practical significance that suggested 'possible benefits' for players born in birth quarter 1 compared with players born in birth quarter 4 in the U13 age group. The benefits in the older age groups for players born in birth quarter 1 were smaller, supported by smaller effect sizes.

The present study revealed that at the highest level of Belgian youth soccer competition (U13-U17) a large relative age effect exists. That is, players born in the first birth quarter of the selection year $(40.1-43.8 \%)$ are more likely to have been selected compared with peers born in the other birth quarters (BQ2: 22.2-27.9\%, BQ3: 16.4-18.5\%, BQ4: 12.3-14.8\%). The birth date distribution of selected players is in contrast to the even distribution of birth dates in the Flemish population. These findings are in agreement with many other studies in Belgian and other European elite youth soccer players $[8,12,22,29]$, where there was a large bias in the proportional distribution of birth date of selected players towards the first quarter of the selection year. Moreover, research from other team sports such as ice hockey, volleyball, basketball and rugby, have also reported skewed birth date distributions towards an earlier birth date from cut-off date $[2,5,25]$.

To date, only a few studies related quarter of birth to physical and physiological capacities and maturation in young soccer players $[4,8,13]$. The results of the present study, among others, suggest that chronologically older players benefit from early recognition from coaches and talent scouts $[11,19,29]$. Indeed, a recent review revealed that the relatively younger sports participants under 14 years of age are less likely to participate in competitive sports [5]. Moreover, it was also suggested that both competitive sports participation and a career in professional sports is less likely for relatively younger individuals. In soccer however, it has been suggested that both the combination of being relatively older and having increased biological maturation status underlie the increased likelihood of being selected in youth soccer $[5,11]$. In addition, interacting psychological factors, linked with selection and experience differences according to relative age have also been presented to account for RAE's. Relatively older players may be more likely to develop higher perceptions of competency and self-efficacy. Otherwise, relatively younger players, faced with consistent sport selection disadvantages may be more likely to have negative experiences, develop low competence perceptions, and thus terminate the sport involvement $[5,23]$.

It has been suggested that both biological maturation and selection of young players within their developmental phase and the organization of soccer competition are responsible for large RAE's observed in team sports such as soccer $[5,11]$. Indeed, many studies in youth sports explain the overrepresentation of players born early in the selection year by their larger anthropometric dimensions and other physical performance advantages, especially in sports where strength, speed and endurance are key factors $[18,23,25]$.

In contrast however, the present results showed no statistical differences in anthropometric characteristics and functional capacities between players across all birth quarters. This finding agrees with a study in 332 Japanese youth soccer players (U10U15) that revealed no differences in height and body mass across the four birth quarters [13]. Additionally, both Malina et al. [19] and Carling et al. [4] found similar results for anthropometric parameters and functional capacities in 39 elite Portuguese soccer players aged 14 years and 160 elite French youth soccer players aged 14-16 years, respectively. Also, Deprez et al. [8] reported no differences in anthropometric characteristics across the four birth quarters in 606 elite Belgian soccer players aged 9-17 years. The lack of difference between the physical characteristics (aerobic and anaerobic) of the athletes of each birth quarter in these studies most likely reflects the pubertal variation within each of the samples [19].

The overrepresentation of players born in the first birth quarter of the selection year compared with the fourth birth quarter has been suggested to be attributed to an identification and selection policy in soccer based on physical qualities rather than technical or tactical skills [11]. However, in the present study, we observed no significant differences in anthropometric dimensions and anaerobic parameters across all birth quarters in all age groups. Moreover, there were no differences in APHV between players of all birth quarters in all age cohorts. Taken together, the present results agree with others who suggested that the relatively small number of players born later in the selection year but with advanced biological maturity are successful in being selected for elite teams $[8,13]$. Therefore, it seems that the relatively youngest soccer players may be able to counteract the RAE (i.e., to cope with the potential physical disadvantages of being born relatively later in the selection year) if they enter puberty at a relatively earlier age than their chronologically older counterparts. To further examine this suggestion, the present sample of soccer players was divided in 3 different maturity groups per age group, based on the APHV: early maturing players (percentile 1-33), average maturing players (percentile 33-66) and late maturing players (percentile 66-100). The distribution of the early, average and late maturing players within each quarter was then analyzed. This analysis demonstrated for all age groups, that within the first birth quarter, late maturing players were overrepresented when compared with early maturing players (U13, late: $41.3 \%$, early: $27.0 \%$; U15, late: $33.3 \%$, early: $30.6 \%$; U17, late: 35.6 , early: $27.3 \%$ ). On the other hand, within the fourth birth quarter, early maturing players were more present when compared with late maturing players (U13, early: $33.3 \%$, late: $27.8 \%$; U15, early: $37.5 \%$, late: $33.3 \%$; U17, early: $36.4 \%$, late: $35.3 \%)$. This suggests that being born in the first birth quarter increases the chance of being present at elite level, independent of the maturation status. However, players born in the last quarter may have increased their chance for selection at the elite level if they enter puberty at a relatively earlier chronological age. We do however acknowledge that this method of categorizing players into maturity groups does not correspond with the method described by Sherar et al. [25] based on equation 3 from Mirwald et al. [20], which defined early maturers as preceding the average APHV by 1 year, average maturers were \pm 1 year from APHV and late maturers were $>1$ 
year after APHV. Moreover, since it has been suggested that soccer systematically excludes late maturing boys and tends to favour early and average maturing players as chronological age and sports specialization increase [17], it is possible that the present sample of elite soccer players might also exclude these late maturing players. Further research should compare different maturity status per birth quarter using skeletal age as classification index (cf. Figueiredo et al. [9]).

Despite the lack of statistical significance between all birth quarters in each age group, analyses of practical significance between the first and fourth birth quarter revealed possible benefits for players born in the first birth quarter, especially in the U13 age group. This has certainly implications for the talent identification and development programs at this age. In the field, the coach does not have the opportunity to account for chronological age and maturity in the evaluation and assessment of young soccer players. Therefore, standard for smallest worthwhile differences (SWD) between birth quarters could assist the coach ( $\odot$ Table 3$)$.

A notable observation was that the differences diminished when players grew older, resulting in smaller effect sizes. Several reasons might account for this observation. First, each player will eventually reach the adult stage and achieve full maturation, levelling off the differences existing in the younger age groups. Second, youth athletes differ in timing and tempo of development, growth and maturation, demonstrating large inter-individual differences in anthropometrical characteristics and physical capacities, independent of the birth quarter the player is born in $[18,20]$. Finally, drop-out of injured players and selection policies in favour of players with similar anthropometrical characteristics and physical capacities could result in more homogeneous birth quarters when players grow older. Further longitudinal research is required to investigate these observations.

The anaerobic performance results obtained in this study are comparable with several previous studies. For example, Vaeyens et al. [30] reported values for SBJ between $170.1 \pm 14.5 \mathrm{~cm}$ and $201.5 \pm 13.6 \mathrm{~cm}$, for U13 and U16 elite Belgian soccer players, respectively. Also, Sporis et al. [26] found similar results for $5-\mathrm{m}$ sprint $(1.39 \pm 0.13 \mathrm{~s}), \mathrm{SBJ}(219.0 \pm 15.2 \mathrm{~cm})$ and $\mathrm{CMJ}$ $(45.7 \pm 3.85 \mathrm{~cm})$ in 45 elite Croatian soccer players. A study with 69 elite Portuguese soccer players, aged 14 years showed similar results on the $30 \mathrm{~m}$ sprint $(4.88 \pm 0.30 \mathrm{~s})$ and $\mathrm{CMJ}(29.3 \pm 4.6 \mathrm{~cm})$ performance [18]. When interpreted in the context of these previous studies, the present results demonstrate high physical performance levels of the young Belgian soccer players.

The present study has its limitations which should be acknowledged. First, other potential predictors of talent, like training history, psychological and sociological characteristics, were not included in the analysis, although these affect the talent identification and selection process. Second, further research concerning the validation of the age at peak height velocity protocol in a soccer population within a large age-range is warranted. The method has in a general population been successfully validated against the golden standard (X-rays, Mirwarld et al. [20]), but not in a soccer-specific sample. These limitations should be considered when considering further research in this area. An individual's maturity status can also be estimated by using X-rays, assessment of secondary sex characteristics or the parent's adult stature $[16,17,28]$. However, these methods also entail ethical, practical, financial and accuracy issues.
The identification and selection policies in the present sample of elite youth soccer players have led to the formation of homogenous groups of players having similar body size dimensions and anaerobic performances, regardless of their birth date within their age group. The present results suggest this selection phenomena may start before the age of 11 years. Unfortunately, this implies that relatively younger players, especially those who have a delayed maturity status are unlikely to develop their sporting potential or continue participation in sports, due to their physical and physiological disadvantages. Likewise, being relatively older provides a performance and selection advantage when assessed or evaluated against age group peers of the same year which increases the likelihood of access to higher levels of competition, training and coaching $[5,12]$. Youth coaches and scouts should be aware that physical and biological maturation is important in the selection process and they should not discriminate against younger or late-maturing players who may develop their abilities later [1]. Therefore we suggest that national soccer associations should implement specific development programs that consider biological maturation and maturity independent performance tests in the identification and selection of youth soccer players. However, in contrast to the statistical lack of differences between birth quarters, analyses of practical significance demonstrated possible practical/clinical differences between birth quarters, especially in the younger age group. Therefore, youth coaches and scouts should be cautious about the estimation of differences between birth quarters because of large discrepancies between statistical and practical/ clinical significance.

\section{References}

1 Baldari C, Di Luigi L, Emerenziani GP, Gallott MC, Sgró P, Guidetti L. Is explosive performance influenced by androgen concentrations in young male soccer players? Br J Sports Med 2009; 43: 191-194

2 Barnsley RH, Thompson AH. Birthdate and success in minor hockey: the key to the NHL. Can J Beh Sci 1988; 20: 167-176

3 Bosco C, Rusko H, Hirvonen J. The effect of extra-load conditioning on muscle performance in athletes. Med Sci Sports Exerc 1986; 18: 415-419

4 Carling C, Le Gall F, Reilly T, Williams AM. Do anthropometric and fitness characteristics vary according to birth date distribution in elite youth academy soccer players? Scand J Med Sci Sports 2009; 19: 3-9

5 Cobley S, Baker J, Wattie N, McKenna J. Annual age-grouping and athlete development: A meta-analytical review of relative age effects in sport. Sports Med 2009; 39: 235-256

6 Cometti G, Maffiuletti NA, Pousson M, Chatard JC, Maffulli N. Isokinetic strength and anaerobic power of elite, subelite and amateur French soccer players. Int J Sports Med 2001; 22: 45-51

7 Council of Europe. Eurofit: European Test of Physical Fitness. Rome: Council of Europe. Committee for the Development of Sport. 1988

8 Deprez D, Vaeyens R, Coutts AJ, Lenoir M, Philippaerts RM. Relative age effect and Yo-Yo IR1 in youth soccer. Int J Sports Med 2012; 33 : 987-993

9 Figueiredo AJ, Gonçalves CE, Coelhoesilva MJ, Malina RM. Youth soccer players, 11-14 years: Maturity, size, function, skill and goal orientation. Ann Hum Biol 2009; 36: 60-73

10 Harriss DJ, Atkinson G. Update - ethical standards in sport and exercise science research. Int J Sports Med 2011; 32: 819-821

11 Helsen WF, Hodges NJ, Van Winckel J, Starkes JL. The roles of talent, physical precocity and practice in the development of soccer expertise. J Sports Sci 2000; 18: 727-736

12 Helsen WF, Van Winckel J, Williams AM. The relative age effect in youth soccer across. Eur J Sports Sci 2005; 23: 629-636

13 Hirose $N$. Relationships among birth-month distribution, skeletal age and anthropometric characteristics in adolescent elite soccer players. J Sports Sci 2009; 27: 1159-1166

14 Hopkins WG. Measures of reliability in sports medicine and science. Sports Med 2000; 30: 1-15 
15 Hopkins WG, Marshall SW, Batterham AM, Hanin J. Progressive statistics for studies in sports medicine and exercise science. Med Sci Sports Exerc 2009; 41: 3-12

16 Khamis HF, Roche AF. Predicting adult stature without using skeletal age: the Khamis-Roche method. Pediatrics 1994; 94: 504

17 Malina RM, Eisenmann JC, Horta L, Rodrigues J, Miller R. Height mass and skeletal maturity of elite Portuguese soccer players aged 11-16 years. J Sports Sci 2000; 18: 685-693

18 Malina RM, Eisenmann JC, Cumming SP, Ribeiro B, Baros J. Maturityassociated variation in the growth and functional capacities of youth football (soccer) players 13-15 years. Eur J Appl Physiol 2004; 91: $555-562$

19 Malina RM, Ribeiro B, Aroso J, Cumming SP. Characteristics of youth soccer players aged 13-15 years classified by skill level. Br J Sports Med 2007; 41: 290-295

20 Mirwald RL, Baxter-Jones AD, Bailey DA, Beunen GP. An assessment of maturity from anthropometric measurements. Med Sci Sports Exerc 2002; 34: 689-694

21 Mohr M, Krustrup P, Bangsbo J. Match performance of high-standard soccer players with special reference to development of fatigue. J Sport Sci 2003; 21: 519-528

22 Mujika I, Vaeyens R, Matthys SPJ, Santisteban J, Goiriena J, Philippaerts $R M$. The relative age effect in a professional football club setting. J Sports Sci 2009; 27: 1153-1158
23 Musch J, Grondin S. Unequal competition as an impediment to personal development: A review of the relative age effect in sport. Dev Review 2001; 21: 147-167

24 Segers V, De Clercq D, Janssens M, Bourgois J, Philippaerts RM. Running economy in early and late maturing youth soccer players does not differ. Br J Sports Med 2008; 42: 289-294

25 Sherar LB, Baxter-Jones ADG, Faulkner RA, Russell KW. Do physical maturity and birth date predict talent in male youth ice hockey players? J Sports Sci 2007; 25: 879-886

26 Sporis $G$, Vučetić $V$, Jovanović $M$, Milanović $Z$, Ručević $M$, Vuleta $D$. Are there any differences in power performance and morphological characteristics of Croatian adolescent soccer players according to the team position? Coll Antrop 2011; 35: 1089-1094

27 Stølen T, Chamari K, Castagna C, Wisløff U. Physiology of soccer: an update. Sports Med 2005; 35: 501-536

28 Tanner JM, Whithouse RH. Clinical longitudinal standards for height, weight, height velocity, weigh velocity, and stages of puberty. Arch Dis Child 1976; 51: 170

29 Vaeyens $R$, Philippaerts RM, Malina RM. The relative age effect in soccer: A match-related perspective. J Sports Sci 2005; 23: 747-756

30 Vaeyens R, Malina RM, Janssens M, Van Renterghem B, Bourgois J, Vrijens J, Philippaerts RM. A multidisciplinary selection model for youth soccer: the Ghent Youth Soccer Project. Br J Sports Med 2006; 40: 928-934 